\title{
Estresse salino e diferentes temperaturas alteram a fisiologia em sementes de Clitoria fairchildiana Howard
}

\author{
Saline stress and different temperatures change physiology in seeds of Clitoria \\ fairchildiana Howard
}

\section{Danilson Correia da Silva ${ }^{\text {I }}$ Edna Ursulino Alves ${ }^{\text {II }}$, Sueli da Silva Santos-Moura ${ }^{\mathrm{III}}$, Marina Matias Ursulino ${ }^{\mathrm{IV}}$, Luciana Rodrigues de Araújov}

\begin{abstract}
Resumo
Clitoria fairchildiana Howard, conhecida popularmente como sombreiro, é uma árvore nativa muito utilizada no paisagismo urbano devido ao rápido crescimento e beleza das flores, além disso, fornece excelente sombra e sua madeira é utilizada para diversas finalidades. Dessa forma, o trabalho foi realizado com o objetivo de determinar a tolerância das sementes de Clitoria fairchildiana Howard ao estresse salino na germinação em diferentes temperaturas. O experimento foi conduzido no Laboratório de Análise de Sementes do Centro de Ciências Agrárias da Universidade Federal da Paraíba, em Areia - PB. Para simular o estresse salino utilizou-se como soluto o cloreto de sódio $(\mathrm{NaCl})$ diluído em água destilada e deionizada para obtenção das concentrações de 0,0 (controle); 1,$5 ; 3,0 ; 4,5 ; 6,0 ; 7,5 ; 9,0$ e $10,5 \mathrm{dS} \mathrm{m}^{-1}$, nas temperaturas de 25 e $30^{\circ} \mathrm{C}$ constantes e $20-30^{\circ} \mathrm{C}$ alternada. Na avaliação dos efeitos dos tratamentos determinaram-se as seguintes características: porcentagem, primeira contagem e índice de velocidade de germinação (IVG), bem como comprimento e massa seca de plântulas (raiz e parte aérea). O delineamento experimental foi inteiramente ao acaso, com os tratamentos dispostos em esquema fatorial $3 \times 8$ (temperaturas e níveis de salinidade), em quatro repetições. A porcentagem de germinação e o vigor das sementes reduziram com o aumento dos níveis de salinidade, no entanto, para aquelas submetidas à temperatura constante de $25^{\circ} \mathrm{C}$ a porcentagem de germinação foi superior em relação às demais. O decréscimo nos níveis de potencial osmótico das soluções salinas $(\mathrm{NaCl})$ no meio germinativo provoca redução na germinação e no vigor das sementes de Clitoria fairchildiana Howard, as quais são classificadas como glicófitas, com moderada tolerância ao sal $\mathrm{NaCl}$.
\end{abstract}

Palavras-chave: Sombreiro; Qualidade fisiológica de sementes; Espécie florestal

\begin{abstract}
Clitoria fairchildiana Howard, popularly known as sombreiro is a native tree widely used in urban landscaping due to its rapid growth and beauty of the its flowers. In addition, it provides excellent shade and its wood is used in many purposes. Thus, the work was carried out with the objective of determining the tolerance of the seeds of Clitoria fairchildiana Howard to salt stress on germination at different temperatures. The experiment was conducted in the Laboratory of Seed Analysis of the Center of Agricultural Sciences of the Federal University of Paraíba, Areia PB state. To simulate the salt stress, sodium chloride $(\mathrm{NaCl})$ diluted in distilled and deionized water to obtain the concentrations of 0.0 (control) was used as the solute; $1.5 ; 3.0 ; 4,5 ; 6.0 ; 7.5 ; 9.0$ and $10.5 \mathrm{dS} \mathrm{m}^{-1}$, at constant 25 and $30^{\circ} \mathrm{C}$ and alternating $20-30^{\circ} \mathrm{C}$ temperatures. In the evaluation of the effects of the treatments, the following characteristics were determined: percentage, first count and germination speed index (IVG), as well as length and dry mass of seedlings (root and shoot). The experimental design was completely at random, with treatments arranged in a $3 \times 8$ factorial scheme (temperatures and salinity levels), in four replications. The percentage of germination and vigor of the seeds reduced with the increasing in the salinity levels, however, for those submitted to a constant temperature of $25^{\circ} \mathrm{C}$ the percentage of germination was higher compared to the others. The decrease in the osmotic potentials of saline solutions $(\mathrm{NaCl})$ in the germination medium causes a reduction in the germination and vigor of the seeds of Clitoria fairchildiana Howard, which are classified as glycophytes, with moderate tolerance to $\mathrm{NaCl}$ salt.
\end{abstract}

Keywords: Sombreiro; Seeds quality; Forest species

Engenheiro Agrônomo, Funcionário Técnico Administrativo da Universidade Federal de Campina Grande, Rua Luiz Grande, s/n, Frei Damião, CEP 58540-000, Sumé (PB), Brasil. danilsonagro@yahoo.com.br (ORCID: 0000-0003-2880-3203)

Engenheira Agrônoma, Dr ㅍ. Brasil. ednaursulino@cca.ufpb.br (ORCID: 0000-0002-7709-3204)

III Engenheira Agrônoma, Drª̣., Pesquisadora Autônoma, Rua Quitéria de Medeiros, 126, CEP 55293-420, Garanhuns (PE), Brasil. suelidasilvasantos@yahoo.com.br (ORCID: 0000-0002-8105-9228)

Engenheira Agrônoma, Dr ${ }^{a}$., Pesquisadora Autônoma, Rua Diógenes Frazão, 824, CEP 63113-592, Crato (CE), Brasil. marina_matias88@yahoo.com.br (ORCID: 0000-0001-7531-5582)

Engenheira Agrônoma, Dr ํ. ., Pesquisadora Autônoma, Rua José Rufino de Almeida, 1027, CEP 58397-000, Areia (PB), Brasil.

lraraujo1@yahoo.com.br (ORCID: 0000-0003-1876-9363) 


\section{Introdução}

Clitoria fairchildiana Howard, sinonímia C. racemosa Lindl., Centrosema spicata Glaz, Clitoria racemosa Benth., Neurocarpum racemosum Pohl e Ternatea racemosa (Benth.) Kuntze, também conhecida como sombreiro, pertencente à família Fabaceae - Papilionoideae, é uma espécie arbórea de médio a grande porte, com copa frondosa e flores atrovioláceas em rácemos pêndulos, cujo fruto é um legume deiscente, com ocorrência principalmente na floresta ombrófila densa na Amazônia, em formações secundárias, com nítida preferência por solos férteis e úmidos, podendo ocorrer em áreas abertas e alteradas (LORENZI, 2002). A espécie possui madeira moderadamente pesada e de média resistência, sendo utilizada na construção civil como divisória de casas, forra, para confecção de brinquedos e caixotaria, e devido às características ornamentais é utilizada na arborização rural e urbana, também é útil nos reflorestamentos heterogêneos destinados à reconstituição da vegetação e recuperação de áreas degradadas (LORENZI, 2002; GUAJARÁ et al., 2003).

A germinação das sementes de C. fairchildiana é fanerocotiledonar, epígea e inicia-se no terceiro dia após a semeadura, com a protrusão da raiz primária, seguida de emergência dos cotilédones, da plúmula e formação da plântula normal aos 26 dias após a semeadura e não há necessidade de tratamentos pré-germinativos porque as sementes não têm dormência (SILVA; MÔRO, 2008; BATTILANI; SANTIAGO; DIAS, 2011).

Em geral, tanto as plantas halófitas (tolerantes à salinidade) como as glicófitas (sensíveis à salinidade) respondem de maneira semelhante ao estresse salino, variando apenas o limite máximo de tolerância ao sal, em que as sementes das halófitas, altamente tolerantes, conseguem germinar em meio com até $8 \%$ de $\mathrm{NaCl}$, enquanto as glicófitas, pouco tolerantes, têm a germinação de suas sementes inibida em meio com apenas 1 a $2 \%$ de $\mathrm{NaCl}$ (UNGAR, 1995).

Os efeitos dos sais no desempenho germinativo de sementes de muitas espécies são conhecidos há muito tempo, com atuação principalmente na redução da porcentagem e velocidade de germinação, bem como efeito tóxico no embrião (CAMPOS; ASSUNÇÃO, 1990), cujo limite de tolerância é variável entre as mesmas. Como por exemplo, a espécie Caesalpinia pyramidalis Tul., manteve a capacidade germinativa de suas sementes em níveis satisfatórios até potenciais de -0,8 a -1,0 MPa, tornando-se nula no potencial de -1,2 MPa (ANTUNES et al., 2011), enquanto o estresse salino simulado com soluções de $\mathrm{NaCl}$ afetou significativamente a germinação de sementes de Chorisia glaziovii O. Kuntze, com decréscimo gradual na porcentagem e velocidade de germinação conforme o aumento das concentrações salinas (GUEDES et al., 2011a).

Dentre os diversos fatores do ambiente físico, a temperatura tem sido considerada como um dos principais responsáveis tanto pela porcentagem final como pelo índice de velocidade de germinação, por afetar a velocidade de absorção de água e a reativação das reações metabólicas, neste sentido, a capacidade germinativa é dependente de limites bem definidos de temperatura, característicos para cada espécie (BEWLEY et al., 2013), de forma que é de interesse ecofisiológico a determinação das temperaturas mínima, ótima e máxima, cujos limites extremos, incluindo a temperatura considerada ótima, representam as temperaturas cardinais para a germinação (MARCOS-FILHO, 2015).

A temperatura também modifica a velocidade das reações químicas que irão mobilizar ou degradar as reservas armazenadas, interferir na síntese de várias substâncias para o crescimento das plântulas (BEWLEY et al., 2013), ou provocar alterações na membrana plasmática. A temperatura constante de $30^{\circ} \mathrm{C}$ foi indicada para condução de testes de germinação em sementes de Parkia pendula (Willd.) Benth. ex Walp. (ROSSETO et al., 2009), Acacia caven (Mol.) Mol. (ESCOBAR et al., 2010), Amburana cearensis (All.) A.C. Smith (GUEDES et al., 2010) e Apeiba tibourbou Aubl. (GUEDES et al., 2011c). A temperatura constante de $25^{\circ} \mathrm{C}$ foi recomendada para teste de germinação em sementes de Clitoria fairchildiana R. A. Howard. (SILVA; CESARINO, 2014), Albizia edwallii (Hoehne) (DUARTE et al., 2015), Parkia multijuga Benth. (ROCHA et al., 2014) e Ocotea odorifera (Vell.) (ZANOTELLI; KISSMANN, 2017). Para sementes de Dalbergia

Ci. Fl., Santa Maria, v. 29, n. 3, p. 1129-1141, jul./set. 2019 
nigra Vell. Fr. All. (GUEDES et al., 2011b), a temperatura indicada para instalação de testes de germinação foi a alternada de $20-30^{\circ} \mathrm{C}$.

Diante do exposto, objetivou-se determinar a tolerância das sementes de Clitoria fairchildiana Howard ao estresse salino na germinação em diferentes temperaturas.

\section{Material e métodos}

O experimento foi realizado no Laboratório de Análise de Sementes (LAS) pertencente ao Departamento de Fitotecnia e Ciências Ambientais do Centro de Ciências Agrárias da Universidade Federal da Paraíba, em Areia - PB. As sementes de Clitoria fairchildiana Howard foram obtidas de frutos colhidos de aproximadamente 10 árvores-matrizes localizadas no campus da UFPB em Areia - PB, com distância mínima de 100 metros. Após a colheita, que foi realizada no mês de outubro, os frutos foram levados ao LAS para a retirada das sementes, mediante abertura manual e eliminação daquelas mal formadas.

Inicialmente, determinou-se a curva de embebição das sementes para cada temperatura pela pesagem sistemática de quatro repetições de 25 sementes em balança analítica digital com precisão de 0,0001 g. Em seguida, as sementes foram distribuídas em rolos de papel-toalha (germitest) e postas em câmara tipo Biological Oxigen Demand (B.O.D.) com fotoperíodo de 8/16 horas de luz e escuro, respectivamente, proporcionado por quatro lâmpadas fluorescentes de 20 $\mathrm{W}$, tipo luz do dia, os quais foram regulados nas temperaturas constantes de 25 e $30^{\circ} \mathrm{C}$ e alternada de $20-30^{\circ} \mathrm{C}$, permanecendo por até 36 horas. As pesagens foram realizadas em intervalos de uma hora até o período de cinco horas, posteriormente a cada seis até 36 horas quando verificou-se a emissão de raiz primária em mais de $50 \%$ das sementes. A embebição foi realizada em rolo de papel com três folhas umedecidas com água destilada, no volume equivalente a 2,5 vezes o seu peso seco e o teor de água calculado de forma indireta, baseando-se no teor de água inicial das sementes e no peso úmido destas nos diferentes intervalos, sendo os resultados expressos em percentagem na forma de gráfico.

Na simulação do estresse salino utilizou-se água destilada e deionizada para diluição do cloreto de sódio $(\mathrm{NaCl})$ e obtenção das concentrações, cujo valor da condutividade elétrica das soluções foi determinado com auxílio de condutivímetro. Os valores de condutividade elétrica da fonte cloreto de sódio foram obtidos pela expressão de Richards (1954) e os valores de condutividade elétrica utilizados foram: 0,$0 ; 1,5 ; 3,0 ; 4,5 ; 6,0 ; 7,5 ; 9,0 ; 10,5 \mathrm{dS} \mathrm{m}^{-1}$. O nível zero foi adotado como testemunha (controle), utilizando-se apenas água destilada para umedecer o substrato, sendo o efeito dos tratamentos avaliados através dos seguintes testes:

Teste de germinação - conduzido com 100 sementes, divididas em quatro repetições de 25 , as quais foram distribuídas sobre duas folhas de papel germitest e cobertas com uma terceira, todas umedecidas com as soluções contendo quantidades preestabelecidas de cloreto de sódio $(\mathrm{NaCl})$ para proporcionar os diferentes níveis de salinidade, além do tratamento com água destilada, na quantidade equivalente a três vezes a massa do papel seco para evitar a reposição de água/soluções porque as sementes eram grandes. Posteriormente, os rolos foram acondicionados em sacos de plástico para evitar a evaporação da solução e mantidos em germinadores tipo B.O.D., regulados para os regimes de temperaturas constantes de 25 e $30^{\circ} \mathrm{C}$ e alternada de $20-30^{\circ} \mathrm{C}$, com fotoperíodo de 8/16 horas de luz e escuro, respectivamente. As avaliações foram realizadas do sétimo até o décimo quarto dia após a instalação do teste, computando-se a porcentagem de plântulas normais, segundo as indicações contidas nas Regras para Análise de Sementes (BRASIL, 2009).

Primeira contagem de germinação - conduzida conjuntamente com o teste de germinação, computando-se as plântulas normais obtidas aos sete dias após a semeadura, sendo os dados expressos em porcentagem.

Índice de velocidade de germinação (IVG) - no mes mo horário foram realizadas contagens diárias das plântulas normais, durante 14 dias, e o índice calculado conforme a fórmula proposta 
por Maguire (1962).

Comprimento e massa seca de plântulas - após a contagem final do teste de germinação, as plântulas normais de cada tratamento e repetição foram medidas da raiz até a parte aérea com auxílio de uma régua graduada em centímetros, sendo os resultados expressos em $\mathrm{cm}$ plântula ${ }^{-1}$. As mesmas plântulas utilizadas para o comprimento foram colocadas em sacos de papel kraft e levadas à estufa regulada a $65^{\circ} \mathrm{C}$ até atingir peso constante ( 48 horas) e, decorrido esse período, as amostras foram pesadas em balança analítica com precisão de $0,001 \mathrm{~g}$, cujos resultados foram expressos em g plântula ${ }^{-1}$.

Delineamento experimental e análise estatística - o delineamento experimental utilizado foi o inteiramente ao acaso, com os tratamentos distribuídos em esquema fatorial $3 \times 8$ (temperaturas e níveis de salinidade), em quatro repetições. Os dados foram submetidos à análise de variância e de regressão polinomial utilizando-se o programa estatístico SAEG.

\section{Resultados e discussão}

O teor de água inicial das sementes de C. fairchildiana era de 39\% e o padrão de embebição foi semelhante nas três temperaturas avaliadas, em que na primeira hora houve um aumento de $6 \%$ no teor de água, seguido de aproximadamente $2 \%$ de aumento até as primeiras cinco horas, sendo que com 12 horas de embebição houve um aumento superior a $24 \%$. A absorção de água foi mais intensa entre 5 e 12 horas de absorção (Figura 1), o que provavelmente esteja relacionado com a fase I da germinação (MARCOS-FILHO, 2015), uma vez que Bewley et al. (2013) relataram que quando a semente seca é colocada em água ocorre uma alta concentração de gradiente de potencial hídrico, que é responsável pelo movimento de água na semente, cuja rápida absorção deve-se ao potencial matricial ser baixo, sendo este considerado o elemento primário responsável pela embebição em sementes, o que justificaria a rápida embebição das sementes de C. fairchildiana em todos as temperaturas.

No intervalo das temperaturas de $20-30$ e $30^{\circ} \mathrm{C}$, a porcentagem de $50 \%$ de protrusão de raiz primária ocorreu com 30 horas de embebição, enquanto na temperatura de $25^{\circ} \mathrm{C}$ esse percentual foi obtido com 36 horas (Figura 1).

Em sementes de Melanoxylon brauna Schott, Flores et al. (2014) verificaram que a temperatura atuou diretamente sobre a velocidade de embebição e na quantidade final de água absorvida, e que a embebição acelerou com o aumento da temperatura, obtendo-se maior quantidade final de água nos tratamentos com temperaturas mais altas $\left(35 \mathrm{a} 45^{\circ} \mathrm{C}\right)$. Para as sementes de Poecilante parviflora Bentham de diferentes tamanhos (grandes, médias e pequenas), Sampaio et al. (2015) também verificaram de forma clara, as três fases fisiológicas de embebição.

A germinação das sementes de Clitoria fairchildiana Howard foi afetada pelos níveis de salinidade testados, constatando-se que na ausência do estresse salino obtiveram-se os maiores percentuais de germinação $(94,97$ e $96 \%)$ nas temperaturas alternada de $20-30^{\circ} \mathrm{C}$ e constantes de 25 e $30^{\circ} \mathrm{C}$, respectivamente (Figura 2). Na situação de estresse salino, as maiores porcentagens de germinação foram obtidas nos níveis de 0,$25 ; 0,090$ e $2,25 \mathrm{dS} \mathrm{m}^{-1}$ nas temperaturas de $20-30^{\circ} \mathrm{C}$ alternada e 25 e $30^{\circ} \mathrm{C}$ constantes, respectivamente, constatando-se ainda redução significativa a partir do nível de salinidade de $6 \mathrm{dS} \mathrm{m}^{-1}$.

A redução na porcentagem de germinação com o aumento do estresse salino pode estar relacionada com a "seca fisiológica" produzida, uma vez que o aumento das concentrações salinas no meio germinativo provoca diminuição do potencial osmótico e, consequentemente, redução do potencial hídrico (RIBEIRO; PELACANI, 2006). Esta redução pode afetar a cinética de absorção de água pelas sementes (efeito osmótico), como também elevar a concentração de íons no embrião (efeito tóxico) a níveis tóxicos (BETONI; SCALON; MUSSURY, 2011). 
Figura 1 - Curva de embebição de sementes de Clitoria fairchildiana Howard submetidas a diferentes temperaturas.

Figure 1 - Imbibition curve of Clitoria fairchildiana Howard seeds subjected to different temperatures.

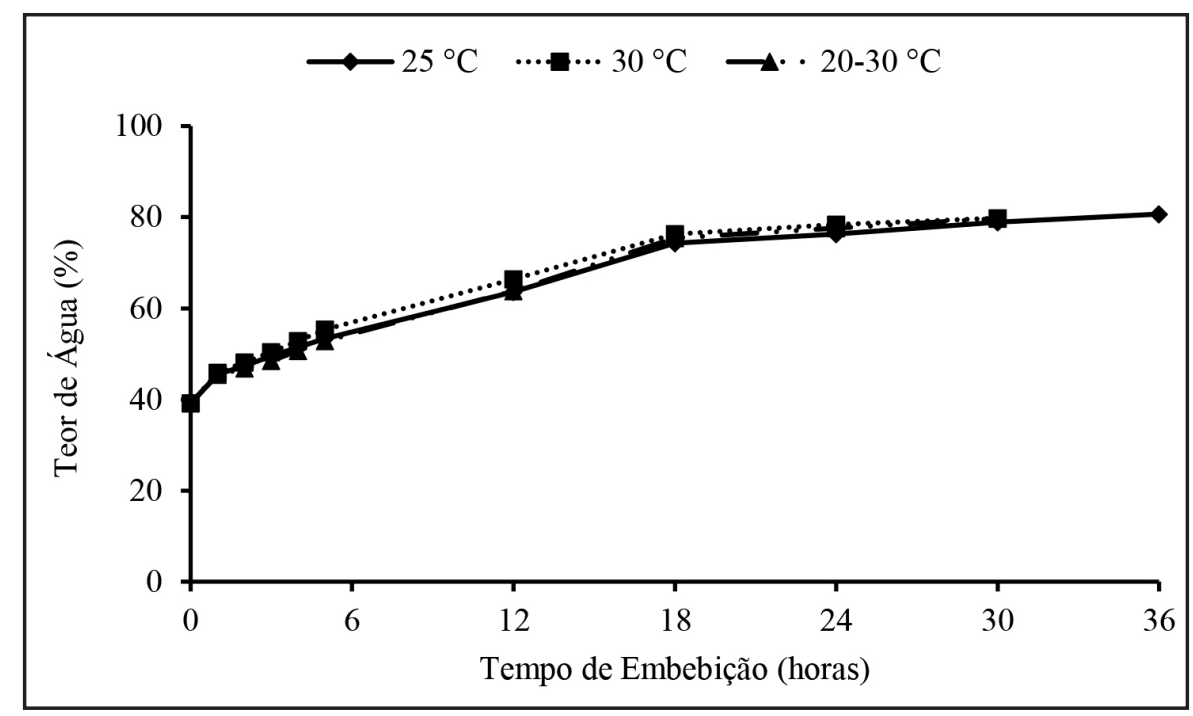

Fonte: Silva et al. (2019)

Figura 2 - Germinação de sementes de Clitoria fairchildiana Howard submetidas a estresse salino em diferentes temperaturas. Fonte: Silva et al. (2019).

Figure 2 - Germination of Clitoria fairchildiana Howard seeds subjected to salt stress under different temperatures.

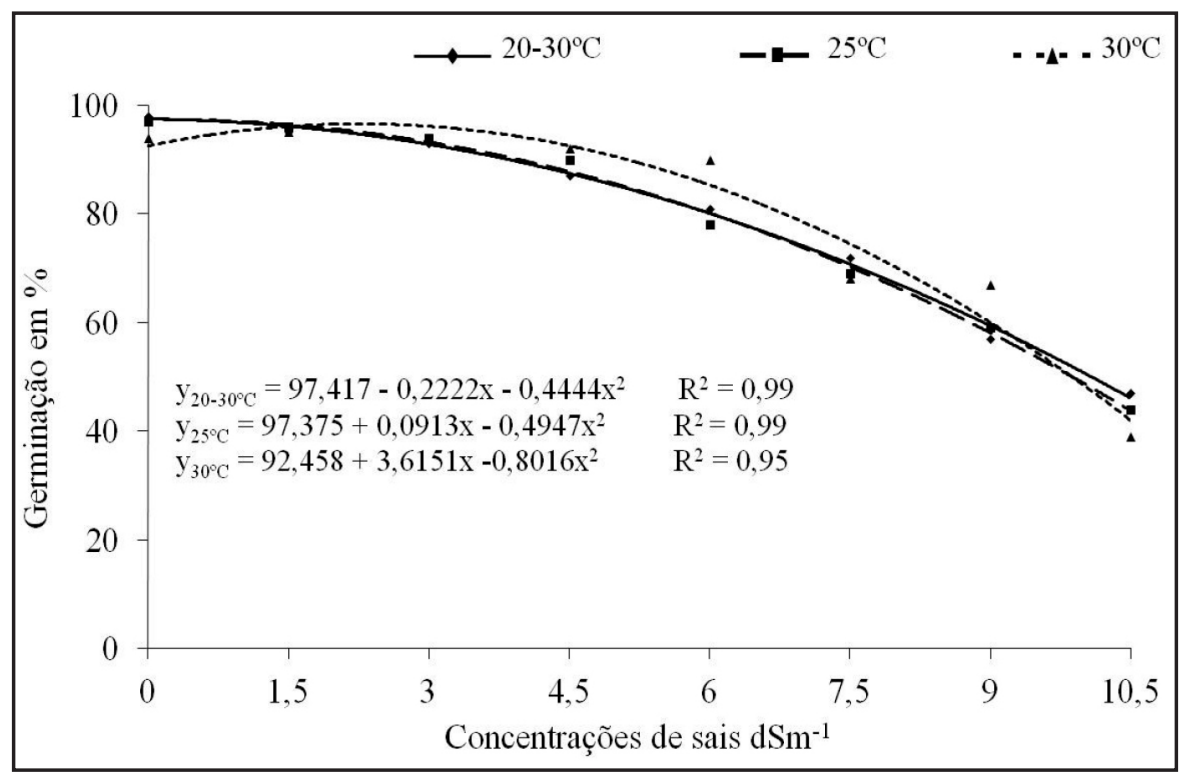

Fonte: Silva et al. (2019)

Os efeitos dos sais sobre a germinação das sementes e sua atuação, principalmente, na 
redução da porcentagem e velocidade de germinação são variáveis para cada espécie, o que torna importante os estudos para identificar os níveis de tolerância e a capacidade de sobrevivência em ambientes com estas características, que no caso da espécie Clitoria fairchildiana Howard constatou-se elevada tolerância. De forma semelhante, o estresse salino simulado com $\mathrm{NaCl}$ também provocou redução na germinação das sementes de Chorisia glaziovii O. Kuntze. (GUEDES et al., 2011a), Guazuma ulmifolia Lam. (BETONI; SCALON; MUSSURY, 2011) e Capparis flexuosa L (PACHECO et al., 2012). No entanto, o mesmo não foi constatado para a espécie Schizolobium amazonicum (Huber ex Ducke) a qual foi classificada como glicófita, ou seja, pouco tolerante aos sais $\mathrm{NaCl}$ e $\mathrm{CaCl}_{2}$ (BRAGA et al., 2008).

Pelos dados da primeira contagem de germinação das sementes Clitoria fairchildiana Howard submetidas a diferentes níveis de salinidade e temperaturas, verificou-se que independentemente das temperaturas testadas, a germinação das sementes por ocasião da primeira contagem reduziu com o aumento das concentrações da solução, sendo mais drástica a partir de $6,0 \mathrm{dS} \mathrm{m}^{-1} \mathrm{de} \mathrm{NaCl}$ (Figura 3). Esse comportamento pode ser explicado devido à influência da temperatura no processo germinativo, podendo ter reduzido o metabolismo das sementes e em conjunto com o efeito tóxico e a seca fisiológica causada pelos níveis de sais, promoveu redução na germinação e atrasa no início do processo germinativo.

\section{Figura 3 -Primeira contagem de germinação (\%) de sementes de Clitoria fairchildiana Howard submetidas ao estresse salino sob diferentes temperaturas.}

Figure 3 - First count of germination (\%) of of Clitoria fairchildiana Howard seeds subjected to salt stress under different temperatures.

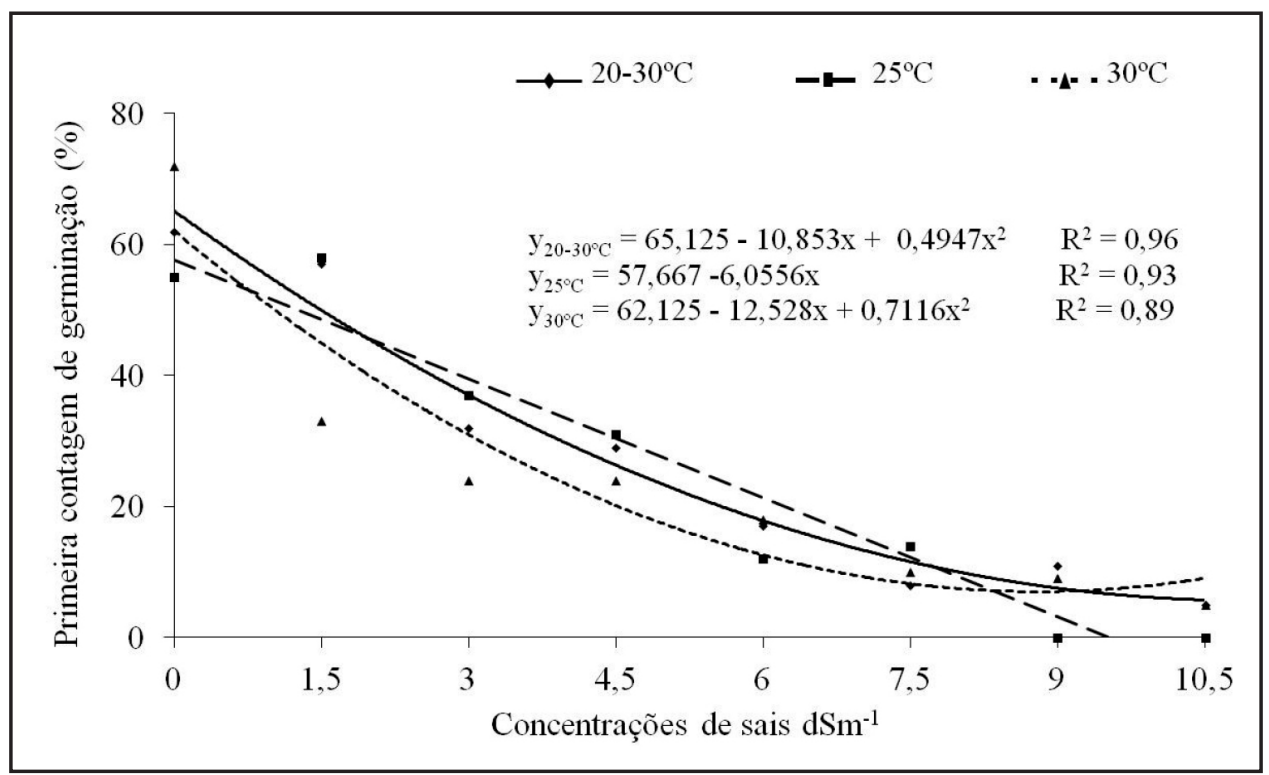

Fonte: Silva et al. (2019)

Em sementes de Calendula officinalis L. Antonello et al.(2008) observaram que a porcentagem de germinação na primeira contagem decresceu conforme aumentou a concentração de $\mathrm{NaCl}$, possivelmente devido à restrição hídrica proporcionada para a cultura, com ligeiro aumento na concentração de $0,011 \mathrm{~mol} \mathrm{dm}^{-3}$. A primeira contagem de germinação das sementes de Chorisia glaziovii O. Kuntze também foi afetada pelas concentrações salinas nas diferentes temperaturas testadas, sendo mais acentuada na temperatura de $30^{\circ} \mathrm{C}$, cujo porcentual de germinação aos cinco dias tornou-se nulo no nível 4,5 $\mathrm{dS} \mathrm{m}^{-1}$ de salinidade (GUEDES et al., 2011a). O aumento 
das concentrações salinas de $\mathrm{NaCl}, \mathrm{KCl}$ e $\mathrm{CaCl} 2$ também reduziu a germinação das sementes de Cedrela odorata L. por ocasião da primeira contagem, sendo que quando foi utilizado $100 \mathrm{mM}$ de concentração de todos os sais a germinação foi nula (FERREIRA et al., 2013).

De forma semelhante ao que ocorreu na germinação e primeira contagem, o índice de velocidade de germinação também foi afetado negativamente pelo aumento dos níveis de sais das soluções de $\mathrm{NaCl}$, independentemente das temperaturas (Figura 4). O índice de velocidade de germinação foi eficiente na indicação dos efeitos negativos, tanto dos níveis de sais como das temperaturas, uma vez que o aumento nas concentrações salinas proporcionou redução na velocidade de germinação. A determinação da tolerância e da capacidade germinativa das sementes em meio salino é importante para identificar as espécies que podem sobreviver em ambientes com estas características. Segundo Ferreira et al. (2013) a germinação das sementes de forma rápida, uniforme e em maior porcentagem é uma característica importante quando se refere à semeadura em campo, uma vez que as sementes quando germinam mais lentamente ficam dispostas às condições adversas do ambiente.

O índice de velocidade de germinação de sementes de Stylosanthes capitata Vog. foi afetado pelos níveis de salinidade aplicados, sendo o efeito mais prejudicial em salinidade a partir de 2,5 dS m ${ }^{-1}$ (OLIVEIRA et al., 2008). Em sementes de Enterolobium schomburgkii (Benth.) Benth., Braga, Sousa e Almeida (2009) constataram reduções mais acentuadas no índice de velocidade de germinação à medida que os potenciais osmóticos de $\mathrm{NaCl}$ tornaram-se mais negativos. A elevação das concentrações salinas reduziu o vigor das sementes de Chorisia glaziovii O. Kuntze, sendo mais acentuada na temperatura de $30^{\circ} \mathrm{C}$ (GUEDES et al., 2011a).

\section{Figura 4 - Índice de velocidade de germinação de sementes de Clitoria fairchildiana Howard submetidas ao estresse salino sob diferentes temperaturas.}

Figure 4 - Germination speed index of Clitoria fairchildiana Howard seeds subjected to salt stress under different temperatures.

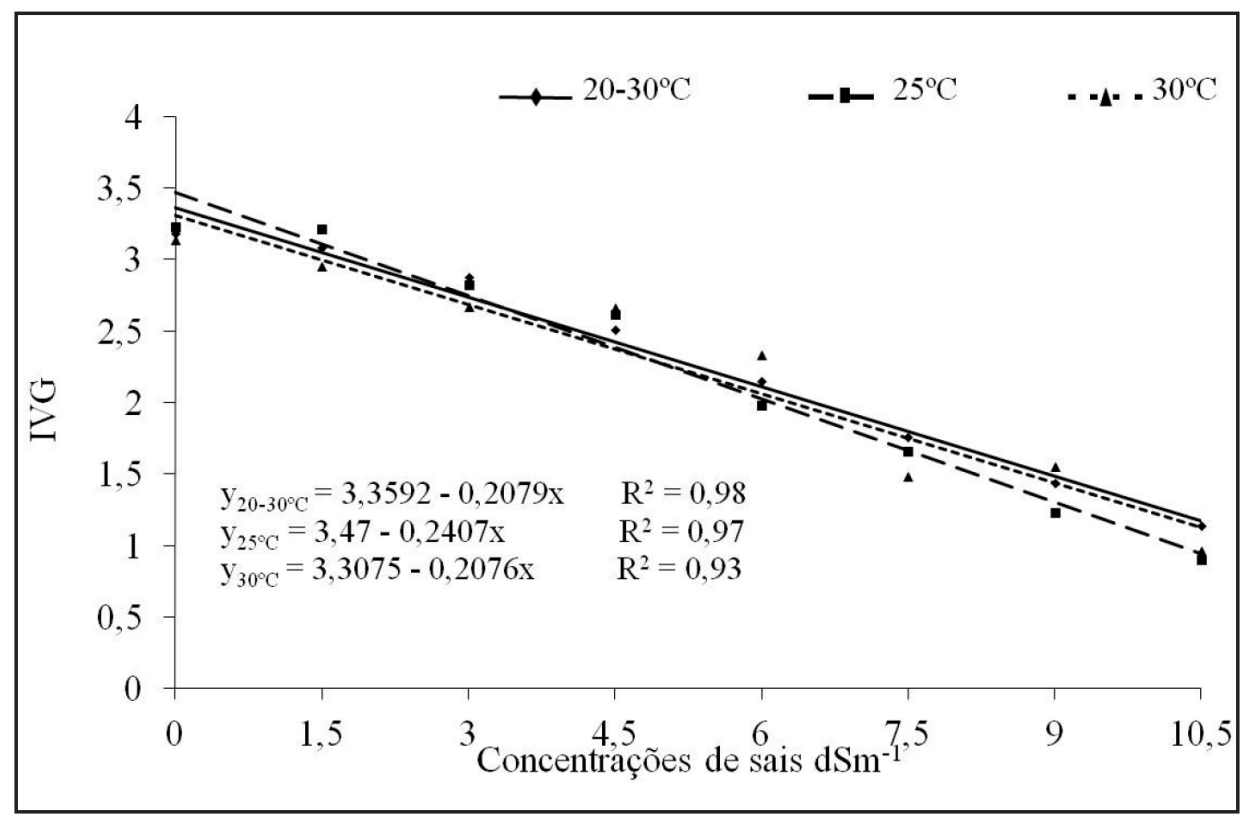

Fonte: Silva et al. (2019)

Para as sementes de Parkinsonia aculeata L., Bezerra et al. (2013) verificaram que os níveis de salinidade no substrato acima de $7 \mathrm{dS} \mathrm{m}^{-1}$ não comprometeram a emergência, o índice de velocidade de emergência nem a produção de clorofila $b$ nas folhas, evidenciando que o limite 
de tolerância da espécie à ação da salinidade durante a germinação e o crescimento inicial foi superior a $7 \mathrm{dS} \mathrm{m}{ }^{-1}$. No entanto, Ferreira et al. (2013) constataram que a velocidade de germinação das sementes de Cedrela odorata L. reduziu a partir da concentração de $25 \mathrm{mM}$ para os sais testados $\left(\mathrm{NaCl}, \mathrm{KCl}\right.$ e $\left.\mathrm{CaCl}_{2}\right)$.

O comprimento da raiz de plântulas de Clitoria fairchildiana Howard também foi afetado negativamente à medida que houve aumento dos níveis de salinidade em todas as temperaturas testadas (Figura 5). Para o comprimento da raiz primária das plântulas originadas de sementes submetidas à temperatura de $25^{\circ} \mathrm{C}$ verificou-se pequena redução até o nível de $4,5 \mathrm{dS} \mathrm{m} \mathrm{m}^{-1}$, por outro lado a temperatura de $20-30^{\circ} \mathrm{C}$ contribuiu para o menor comprimento da raiz em todas as concentrações salinas testadas, enquanto que na temperatura de $30^{\circ} \mathrm{C}$ verificou-se redução no comprimento da raiz a partir da concentração de $6 \mathrm{dS} \mathrm{m}^{-1}$.

O comportamento do crescimento radicular das plântulas de Clitoria fairchildiana Howard foi diferenciado conforme a temperatura testada, sendo mais favorecido na temperatura de $25^{\circ} \mathrm{C}$ até o nível de salinidade de $4,5 \mathrm{dS} \mathrm{m}^{-1}$, provavelmente nas temperaturas mais elevadas o efeito da salinidade seja mais pronunciado, o que prejudica o crescimento do sistema radicular. Segundo Larcher (2004), a primeira e mais sensível resposta à deficiência hídrica é a diminuição da turgescência e, associada a esse evento, a redução do processo de crescimento, especialmente o crescimento em extensão.

\section{Figura 5 - Comprimento de raiz de plântulas de Clitoria fairchildiana Howard oriundas de sementes submetidas ao estresse salino sob diferentes temperaturas.}

Figure 5 - Root length of Clitoria fairchildiana Howard seedlings subjected to salt stress and different temperatures.

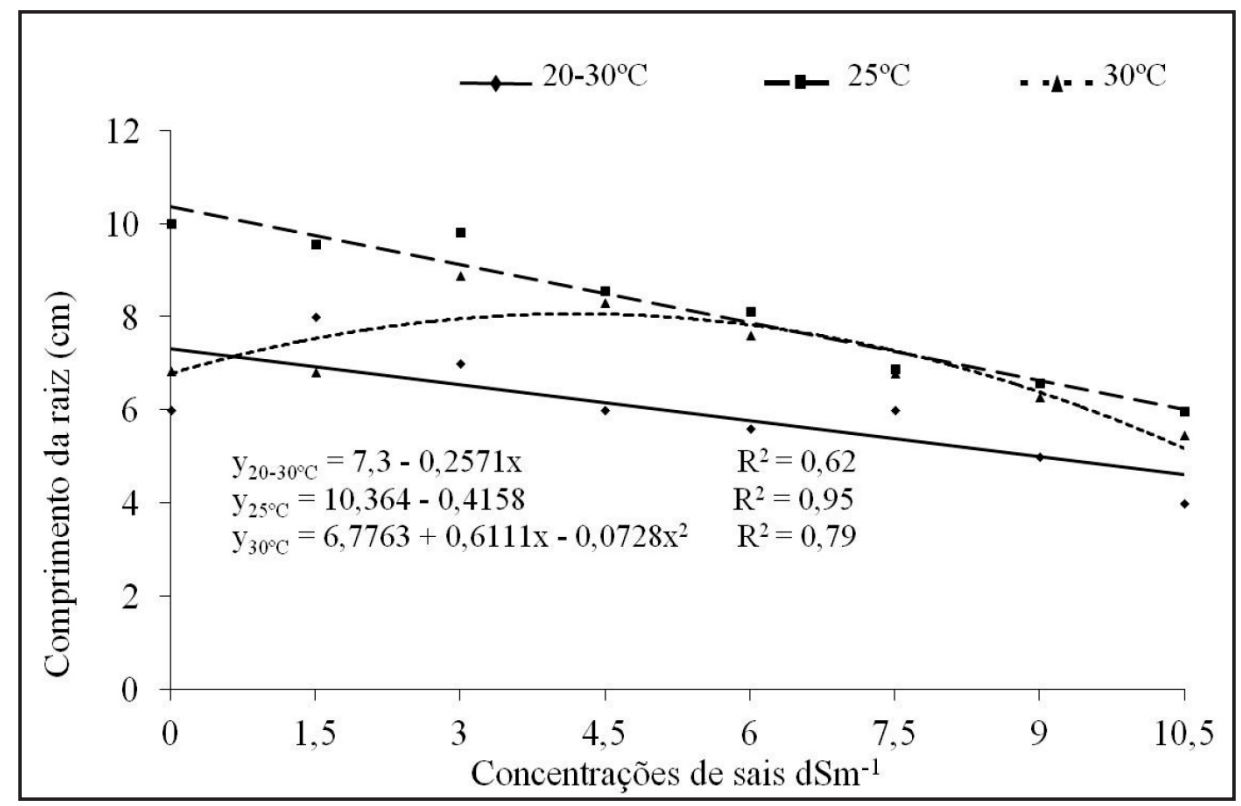

Fonte: Silva et al. (2019)

Os efeitos negativos do estresse salino simulado com $\mathrm{NaCl}$ também foi verificado em outras espécies, uma vez que reduziu o comprimento das plântulas de Chorisia glaziovii O. Kuntze nas temperaturas de $25,30,35,20-30$, sendo menos acentuados na temperatura de $25^{\circ} \mathrm{C}$ (GUEDES et al., 2011a). Para Cupania vernalis Cambess, Lemes et al. (2012) verificaram que os níveis de salinidade $(-0,4$ e $-0,8 \mathrm{MPa})$ não afetaram a produção de massa seca da parte aérea e raízes das plântulas, contudo, a partir do potencial -1,2 MPa houve decréscimo expressivo. O crescimento das raízes primárias das plântulas de Cedrela odorata L. reduziu a partir da concentração de 50 
mM (1,98 cm) do sal KCl (FERREIRA et al., 2013).

O comprimento da parte aérea de plântulas de Clitoria fairchildiana Howard foi afetado com o aumento dos níveis de salinidade, independentemente da temperatura avaliada. Os maiores comprimentos $(8,11 ; 9,39$ e $8,83 \mathrm{~cm})$ foram obtidos no nível zero de salinidade nas temperaturas alternada de $20-30^{\circ} \mathrm{C}$ e constantes de 25 e $30^{\circ} \mathrm{C}$, respectivamente, com reduções drásticas a partir do nível de salinidade de $4,5 \mathrm{~d} \mathrm{Sm}^{-1}$ (Figura 6). Estes resultados comprovam que o crescimento das plântulas desta espécie é afetado em ambiente salino, contudo, a redução da parte aérea é maior quando comparada à raiz, provavelmente pelo fato de o estresse salino reduzir a disponibilidade de água necessária para o crescimento das plântulas e, as mesmas investirem mais no crescimento da raiz com a finalidade de melhorar a eficiência da absorção de água e, consequentemente, garantir a sua sobrevivência, sendo esta, portanto, uma característica de adaptação desta espécie à deficiência hídrica e a outros fatores do ambiente.

\section{Figura 6 - Comprimento da parte aérea de plântulas de Clitoria fairchildiana Howard oriundas} de sementes submetidas ao estresse salino sob diferentes temperaturas.

Figure 6 - Shoot length of Clitoria fairchildiana Howard seedlings subjected to salt stress under different temperatures.

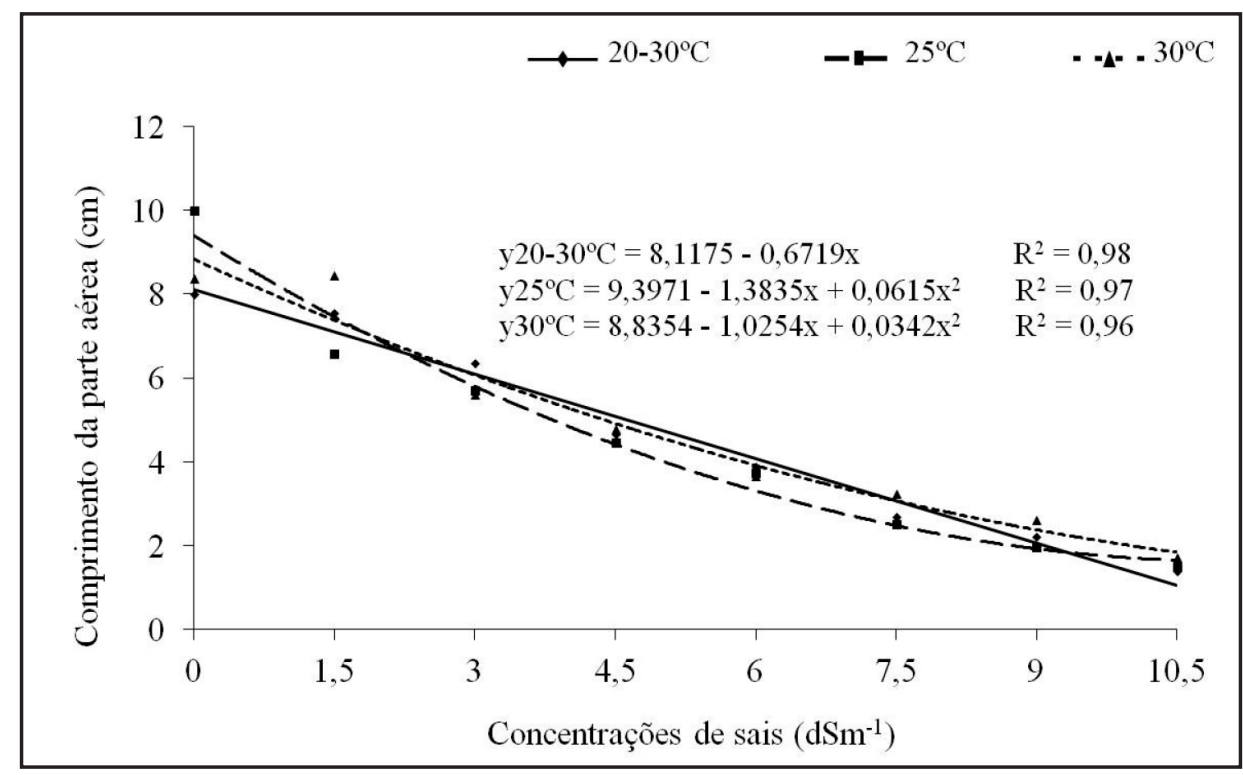

Fonte: Silva et al. (2019)

Os efeitos do estresse salino são diferenciados em função da espécie, por exemplo em Zizyphus joazeiro Mart., Lima e Torres (2009) observaram que a partir do potencial osmótico de -0,6 MPa de $\mathrm{NaCl}$ não ocorreu crescimento significativo da plântula, enquanto para Chorisia glaziovii O. Kuntze, Guedes et al. (2011a) verificaram comportamento semelhante da parte aérea e raízes das plântulas, cujo melhor desempenho ocorreu nas temperaturas de $25,20-30$ e $30^{\circ} \mathrm{C}$ no tratamento controle $(8,47 ; 7,68$ e $6,99 \mathrm{~cm}$, respectivamente).

Com relação ao conteúdo de massa seca das raízes de plântulas de Clitoria fairchildiana Howard (Figura 7), verificou-se comportamento semelhante em todas as temperaturas testadas, não havendo variação significativa entre os níveis de salinidade e as temperaturas de 20-30 e $25^{\circ} \mathrm{C}$, cujo conteúdo médio foi 0,018 e $0,024 \mathrm{~g}$, respectivamente; apenas os dados da temperatura constante de $30^{\circ} \mathrm{C}$ se ajustaram ao modelo de regressão, com reduções no conteúdo de massa seca a partir do nível de salinidade de $3 \mathrm{dS} \mathrm{m}^{-1} \mathrm{de} \mathrm{NaCl}$. 


\section{Figura 7 - Massa seca das raízes de plântulas de Clitoria fairchildiana Howard oriundas de sementes submetidas ao estresse salino sob diferentes temperaturas.}

Figure 7 - Dry weight of roots of Clitoria fairchildiana Howard seedlings subjected to salt stress under different temperatures.

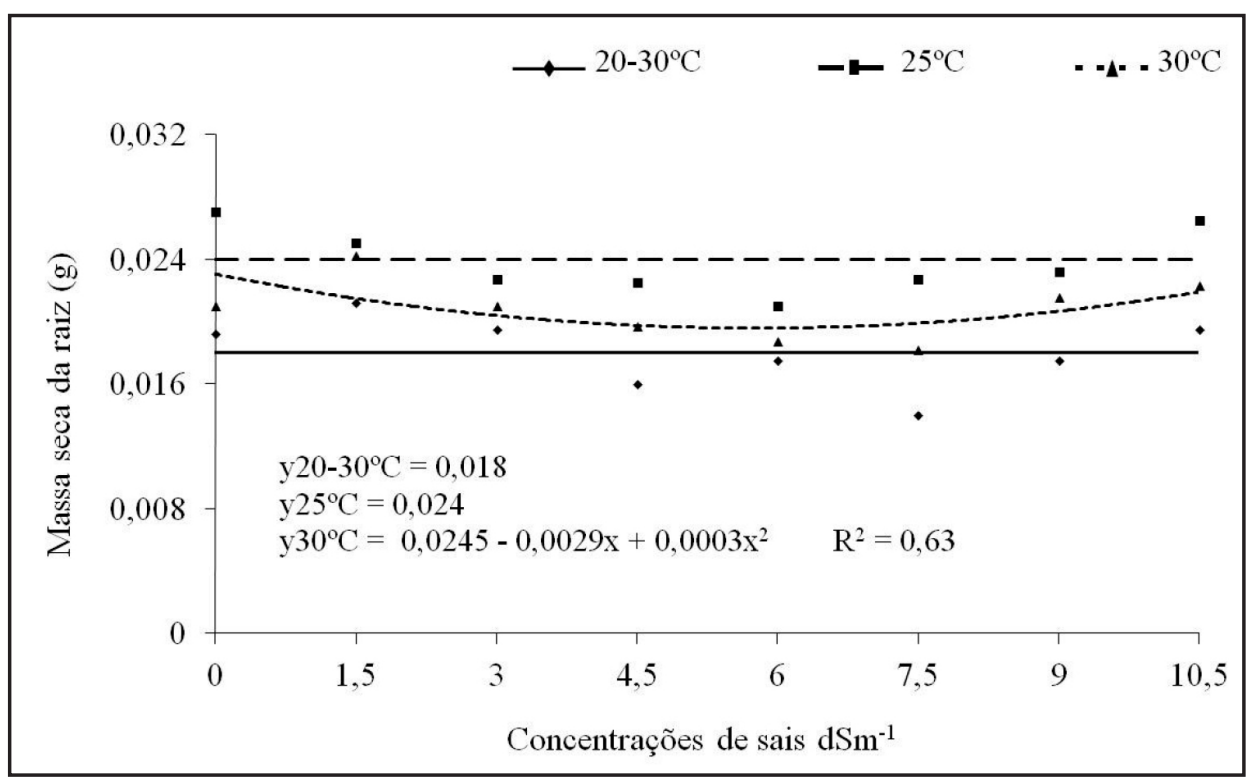

Fonte: Silva et al. (2019)

Analisando-se os dados de massa seca da parte aérea de plântulas de Clitoria fairchildiana Howard (Figura 8) observou-se redução linear à medida que se aumentou os níveis de salinidade nas temperaturas alternada de $20-30^{\circ} \mathrm{C}$ e constante de $25^{\circ} \mathrm{C}$. A temperatura de $20-30^{\circ} \mathrm{C}$ foi a que proporcionou o maior conteúdo de massa seca $(0,0635 \mathrm{~g})$ no tratamento-controle. Martins, Nakagawa e Bovi (1999) afirmaram que a determinação da massa seca de plântulas é uma maneira de avaliar o seu crescimento, no qual se consegue determinar, com precisão, a transferência de reservas da semente para o eixo embrionário, de forma que as amostras com maior massa seca são consideradas de maior vigor.

O maior conteúdo de massa seca nos tratamentos citados pode ser explicado pelo fornecimento das condições necessárias à germinação, devido às sementes originarem plântulas com maior taxa de crescimento, em função da maior capacidade de transformação e suprimento de reservas dos tecidos de armazenamento e maior incorporação destes pelo eixo embrionário (DAN et al., 1987; NAKAGAWA, 1999). A pesar da parte aérea das plântulas de Clitoria fairchildiana Howard ter obtido menor crescimento, constatou-se maior acúmulo de massa seca, quando comparado com a massa seca da raiz em resposta ao estresse salino. Resultados semelhantes foram observados por Lemes et al. (2012) para a espécie Cupania vernalis Cambess, em que o acúmulo de massa seca foi mais expressivo na parte aérea do que nas raízes porque a massa seca destas foi significativamente reduzida com o aumento da salinidade.

De forma geral, as sementes de Clitoria fairchildiana Howard submetidas ao estresse salino demonstraram alta tolerância, uma vez que as concentrações salinas utilizadas não permitiram identificar o nível máximo de tolerância a esse tipo de estresse, já que a germinação no nível de $10,5 \mathrm{dS} \mathrm{m}^{-1}$ foi em torno de $40 \%$ em todas as temperaturas testadas, sendo um valor alto e confere à espécie um caráter adaptativo, com maior capacidade de sobrevivência e estabelecimento das plântulas em ambientes com estas características. 
Figura 8 - Massa seca da parte aérea de plântulas de Clitoria fairchildiana Howard oriundas de sementes submetidas ao estresse salino sob diferentes temperaturas.

Figure 8 - Dry weight of shoots of Clitoria fairchildiana Howard seedling subjected to salt stress under different temperatures.

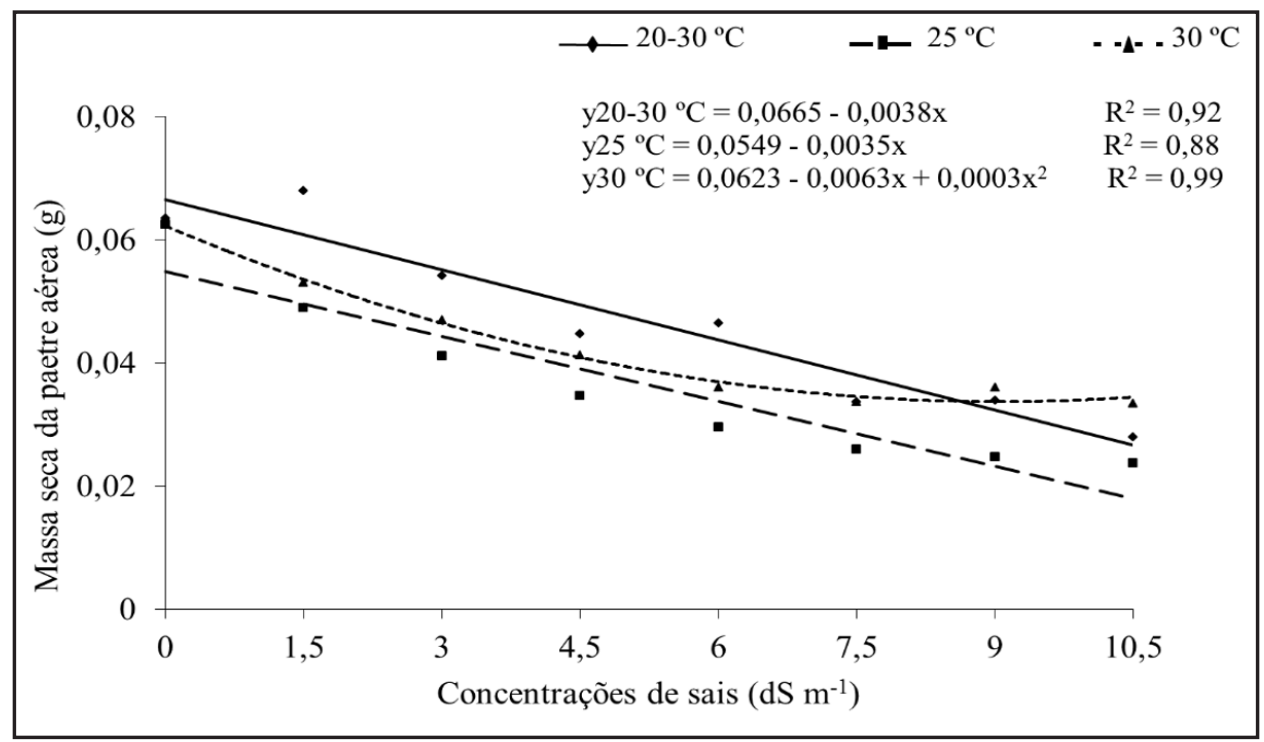

Fonte: Silva et al. (2019)

\section{Conclusões}

O decréscimo dos níveis de potencial osmótico das soluções salinas $(\mathrm{NaCl})$ no meio germinativo provoca redução da viabilidade e vigor das sementes de Clitoria fairchildiana Howard;

$\mathrm{Na}$ temperatura de $25^{\circ} \mathrm{C}$ a germinação e o vigor das sementes de $C$. fairchildiana submetidas a estresse salino são pouco afetados; sal $\mathrm{NaCl}$.

A espécie Clitoria fairchildiana é classificada como glicófita, com moderada tolerância ao

\section{Referências}

ANTONELLO, L. M. et al. Efeito do estresse salino na germinação de sementes de calêndula (Calendula officinalis L.). Revista Brasileira de Plantas Medicinais, Botucatu, v. 10, n. 4, p. 117$120,2008$.

ANTUNES, C. G. C. et al. Germinação de sementes de Caesalpinia pyramidalis Tul. (catingueira) submetidas a deficiência hídrica. Revista Árvore, Viçosa, MG, v. 35, n. 5, p. 1007-1015, 2011.

BATTILANI, J. L.; SANTIAGO, E. F.; DIAS, E. S. Morfologia de frutos, sementes, plântulas e plantas jovens de Guibourtia hymenifolia (Moric.) J. Leonard (Fabaceae). Revista Árvore, Viçosa, MG, v. 35, n. 5, p. 1089-1098, 2011.

BETONI, R.; SCALON, S. P. Q.; MUSSURY, R. M. Salinidade e temperatura na germinação e vigor de sementes de mutambo (Guazuma ulmifolia Lam.) (Sterculiaceae). Revista Árvore, Viçosa, MG, v. 35, n. 3, p. 605-616, 2011.

BEWLEY, J. D. et al. Seeds: physiology of development, germination and dormancy. Nova York: Springer, 2013. $392 \mathrm{p}$. 
BEZERRA, F. T. C. et al. Emergência e crescimento inicial de plantas de Parkinsonia aculeata L. (Fabaceae) em substrato salino. Revista Árvore, Viçosa, MG, v. 37, n. 4, p. 611-618, 2013.

BRAGA, L. F.; SOUSA, M. P.; ALMEIDA, T. A. Germinação de sementes de Enterolobium schomurgkii (Benth.) Benth. submetidas a estresse salino e aplicação de poliamina. Revista Brasileira de Plantas Medicinais, Botucatu, v. 11, n. 1, p. 63-70, 2009.

BRAGA, M. P. S. et al. Germinação de sementes de pinho-cuiabano sob deficiência hídrica com diferentes agentes osmóticos. Scientia Forestalis, Piracicaba, v. 36, n. 78, p. 157-163, 2008.

BRASIL. Ministério da Agricultura, Pecuária e Abastecimento. Regras para Análise de Sementes. Secretaria de Defesa Agropecuária. Brasília: MAPA/ACS, 2009. 395 p.

CAMPOS, I. S.; ASSUNÇÃO, M. V. Efeito do cloreto de sódio na germinação e vigor de plântulas de arroz. Pesquisa Agropecuária Brasileira, Brasília, v. 25, n. 6, p. 837-843, 1990.

DAN, E. L. et al. Transferência de matéria seca como modo de avaliação do vigor de sementes de soja. Revista Brasileira de Sementes, Brasília, v. 9, n. 3, p. 45-55, 1987.

DUARTE, M. M. et al. Germinação e morfologia de sementes e plântulas de Albizia edwallii (Hoehne) Barneby \& J. W. Grimes. Revista Caatinga, Mossoró, v. 28, n. 3, p. 166-173, 2015.

ESCOBAR, T. A. et al. Superação de dormência e temperaturas para germinação de sementes de Acacia caven (Mol.) Mol. (espinilho). Revista Brasileira de Sementes, Lavras, v. 32, n. 2, p. 124$130,2010$.

FERREIRA, E. G. B. S. et al. Processo germinativo e vigor de sementes de Cedrela odorata L. sob estresse salino. Ciência Florestal, Santa Maria, v. 23, n. 1, p. 99-105, 2013.

FLORES, A.V. et al. Germinação de sementes de Melanoxylon brauna Schott em diferentes temperaturas. Revista Árvore, Viçosa, MG, v. 38, n. 6, p. 1147-1154, 2014.

GUAJARÁ, M. et al. Aspectos da biologia de Euphalerus clitoriae Burckhardt \& Guajará, 2000 (Hemiptera: Psyllidae) sob condições de campo. Floresta e Ambiente, Seropédica, v. 10, n. 1, p. 69-75, 2003.

GUEDES, R. S. et al. Estresse salino e temperaturas na germinação e vigor de sementes de Chorisia glaziovii O. Kuntze. Revista Brasileira de Sementes, Lavras, v. 33, n. 2, p. 279-288, 2011a.

GUEDES, R. S. et al. Germinação de sementes de Dalbergia nigra (Vell.) Fr. All. Acta Scientiarum. Biological Sciences, Maringá, v. 33, n. 4, p. 445-450, 2011 b.

GUEDES, R. S. et al. Tratamentos pré-germinativos e temperaturas para a germinação de sementes de Apeiba tibourbou Aubl. Revista Brasileira de Sementes, Lavras, v. 33, n. 1, p. 131140, 2011c.

GUEDES, R. S. et al. Umedecimento do substrato e temperatura na germinação e vigor de sementes de Amburana cearensis (All.) A.C. Smith. Revista Brasileira de Sementes, Lavras, v. 32, n. 3, p. 116-122, 2010.

LARCHER, W. Ecofiosiologia vegetal. São Carlos: Rima, 2004. 531 p.

LEMES, E. Q. et al. Qualidade fisiológica de Cupania vernalis cambess sob diferentes níveis de salinidade. Revista Trópica: Ciências Agrárias e Biológicas, v. 6, n. 3, p. 144-153, 2012.

LIMA, B. G.; TORRES, S. B. Estresse hídrico e salino na germinação de sementes de Zizyphus joazeiro Mart. (Rhamnaceae). Revista Caatinga, Mossoró, v. 22, n. 4, p. 93-99, 2009.

LORENZI, H. Árvores brasileiras: manual de identificação e cultivo de plantas arbóreas nativas do Brasil. 4. ed. Nova Odessa: Instituto Plantarum, 2002. v. 1, 384 p.

MAGUIRE, J. D. Speed of germination-aid in selection and evaluation for seedling emergence vigor. Crop Science, Madson, v. 2, n. 2, p. 176-177, 1962. 
MARCOS-FILHO, J. Fisiologia de sementes de plantas cultivadas. Piracicaba: FEALQ, 2015. 590 p.

MARTINS, C. C.; NAKAGAWA, J.; BOVI, M. L. A. Efeito da posição da semente no substrato e no crescimento inicial das plântulas de palmito-vermelho (Euterpe espiritosantensis Fernandes Palmae). Revista Brasileira de Sementes, Londrina, v. 21, n. 1, p. 164-173, 1999.

NAKAGAWA, J. Testes de vigor baseados no desempenho das plântulas. In: KRZYZANOWSKI, F. C.; VIEIRA, R. D.; FRANÇA NETO, J. B. (ed.). Vigor de sementes: conceitos e testes. Londrina: ABRATES, 1999. p. 2.1-2.24.

OLIVEIRA, F. A. et al. Efeito da água salina na germinação de Stylosanthes capitata Vogel. Revista Verde de Agroecologia e Desenvolvimento Sustentável, Mossoró, v. 3, n. 1, p. 77-82, 2008.

PACHECO, M. V. et al. Germinação e vigor de sementes de Capparis flexuosa L. submetidas ao estresse salino. Revista Brasileira de Ciências Agrárias, Recife, v. 7, n. 2, p. 301-305, 2012.

RIBEIRO, R. C.; PELACANI, C. R. Influência do manitol e $\mathrm{NaCl}$ na germinação de sementes de duas espécies de leguminosas com importância no semi-árido baiano. Sitientibus Série Ciências Biológicas, Feira de Santana, v. 6, n. 2, p. 105-109, 2006.

RICHARDS, L. A. Diagnóstico y rehabilitacion de suelos salinos y sádicos. México: Departamento de Agricultura de los Estados Unidos de América, 1954. 172 p. (Manual de agricultura, 60).

ROCHA, C. R. M. et al. Morfobiometria e germinação de sementes de Parkia multijuga Benth. Nativa, Sinop, v. 2, n. 1, p. 42-47, 2014.

ROSSETO, J. et al. Germinação de sementes de Parkia pendula (Willd.) Benth. ex Walp. (Fabaceae) em diferentes temperaturas. Revista Árvore, Viçosa, MG, v. 33, n. 1, p. 47-55, 2009.

SAMPAIO, M. F. et al. Curva de absorção em sementes de coração de negro (Poecilanthe parviflora Benth.) para três grupos de tamanhos de sementes. Revista Farociência, Porto Velho, v. 2, n. 1, p. 28-37, 2015.

SILVA, B. M. S.; MÔRO, F. V. Aspectos morfológicos do fruto, da semente e desenvolvimento pós-seminal de faveira (Clitoria fairchildiana R. A. Howard. - Fabaceae). Revista Brasileira de Sementes, Pelotas, v. 30, n. 3, p. 195-201, 2008.

SILVA, B. M.; CESARINO, F. Germinação de sementes e emergência de plântulas de faveira (Clitoria fairchildiana R. A. Howard. - Fabaceae). Biota Amazônia, Macapá, v. 4, n. 2, p. 9-14, 2014.

UNGAR, I. A. Seed germination and seed-bank ecology of halophytes. In: KIGEL, J.; GALILI, G. (ed.). Seed development and germination. New York: Marcel Dekker, 1995. p. 599-629.

ZANOTELLI, P.; KISSMANN, C. Germinação de sementes de Ocotea odorifera (Vell.) Rohwer: temperatura de incubação e tratamentos pré-germinativos. Ciência e Natura, Santa Maria, v. 39 n. 1, p. 16-21, 2017. 